\title{
AMINO ACID PROFILING IN EDIBLE SHOOTS OF SOME BAMBOO SPECIES BY USING RP-UHPLC AND THEIR THERAPEUTICAL ASPECTS
}

\author{
KANCHAN RAWAT RANA ${ }^{1 *}$, NIRMALA CHONGTHAM ${ }^{1}$, MADHO SINGH BISHT ${ }^{2}$, AJAY PATIAL ${ }^{3}$ \\ SAVITA VERMA ATTRI ${ }^{3}$
}

\begin{abstract}
${ }^{1}$ Department of Botany, Panjab University, Chandigarh, India. ${ }^{2}$ Department of Environment Studies, North-Eastern Hill University, Shillong, Meghalaya, India. ${ }^{3}$ Department of Pediatrics, Postgraduate Institute of Medical Education and Research, Chandigarh, India. Email: kanchanr580@gmail.com

Received: 20 June 2021, Revised and Accepted: 28 August 2021
\end{abstract}

\begin{abstract}
Objective: This study was conducted to assess the amino acid profiles of edible shoots of five species of bamboos growing in various geographical regions of India.

Methods: Qualitative and quantitative estimation of free amino acids was done by Reverse Phase-Ultra High Performance Liquid Chromatography (RP-UHPLC). Separation of amino acids was carried out using Zorbax eclipse plus C18 Reverse Phase $(1.8 \mu \mathrm{m}), 50 \mathrm{~mm} \times 2.1 \mathrm{~mm}$ column on quaternary UHPLC system using modified gradient elution. Derivatization was done by using auto-sampler Agilent's 1290 infinity. Data assortment and processing were accomplished by using Open Lab Chromatography Data System EZchrome edition, version A.04.06 (Agilent technologies, USA)

Results: In the study, 19 free amino acids were identified, eight essential, five conditionally essential, and six non-essential amino acids (EAA). The principal amino acids were tyrosine (29.41-74.64 $\mu \mathrm{g} / \mathrm{mg}$ d.w.) and asparagine (12.81-111.04 $\mu \mathrm{g} / \mathrm{mg}$ d.w.). The amount of EAAs ranged from 0.46 to $21.11 \mu \mathrm{g} / \mathrm{mg}$ d.w. For the $1^{\text {st }}$ time, taurine and ornithine are reported in bamboo shoots. The analysis exhibited significant variation ( $<<0.05$ ) in free amino acids content among the five studied species. Of the five species, Phyllostachys mannii was best compared to the other species in amino acid
\end{abstract} content.

Conclusion: Results showed superior amino acid composition of bamboo shoots that can be utilized to improve nutritional value of functional foods. Amino acids have various health and therapeutic properties can contribute to the basis for further expansion of these bamboos and imminent potential in applications of food and pharmaceuticals.

Keywords: Amino acids, Bamboo shoots, Nutrition, Health, Bambusa, Dendrocalamus, Phyllostachys.

(C) 2021 The Authors. Published by Innovare Academic Sciences Pvt Ltd. This is an open access article under the CC BY license (http://creativecommons.org/ licenses/by/4.0/) DOI: http://dx.doi.org/10.22159/ajpcr.2021v14i10.42606. Journal homepage: https://innovareacademics.in/journals/index.php/ajpcr

\section{INTRODUCTION}

Dietary protein plays a vital role in regulating metabolic well-being as well as promoting health and longevity in humans. Proteins are made up of different amino acids and therefore the nutritional quality of a food protein is based on the quantity and quality of its specific amino acid composition [1]. Amino acids are essential nutrients in diets, prerequisite not only for the synthesis of protein but as precursors for synthesis of many bioactive molecules that participate in the regulation of signaling pathways and metabolism in the body [2,3]. Studies have revealed that a balanced essential amino acid (EAA) formulation is highly anabolic and important for muscle repair and recovery $[4,5]$. Recent studies indicate that amino acids are vital for their usage as nutritional supplements and have therapeutic potential due to their role in maintaining normal physiological, biochemical, and homeostatic mechanisms [6,7]. Amino acids have antioxidant, antimicrobial, and antiinflammatory properties [8-10]. From nutritional insight, out of twenty amino acids that are necessary for the formation of human proteins, nine are essential as they are not synthesized de novo by humans and need to be obtained from plant-based sources [11]. Despite their nutritional significance, EAAs such as lysine and methionine are lacking in several major crops such as cereals and legumes. On the other hand, animal proteins are expensive with inadequate provision [12]. Over the years, attention and research have been engrossed toward finding an alternative source of amino acids from several wild, underutilized plants as there is an increasing practice of formulation of food products with free amino acids [13].
Bamboo is one such underutilized plant which has been used as a source of food and also for innumerable traditional system of medication for several ailments in ancient China, Tibet, and India [14]. A multiutility and fast-growing plant, bamboo is a member of subfamily Bambusoideae of grass family Poaceae which grows effectively in a wide range of environmental conditions from drier to cooler regions and is subsequently distributed in the tropical, subtropical, and temperate zones. Newly emerging young culms which grow from the nodes of the underground rhizome of bamboo plant are called as bamboo shoots. Recently, bamboo shoots have attained an abundant cognizance worldwide due to existence of nutrients and numerous active phytochemicals which proved to have functional activities and thus allied with health promotion and disease prevention $[15,16]$. Globally, about 100 bamboo species which belongs to few genera, i.e., Bambusa, Dendrocalamus, and Phyllostachys are generally cultivated, preferred, and exploited for their edible shoots [17]. In the present study, five species belonging to three genera were subjected to amino acid analysis. They vary in their habits and morphologies and are categorized into monopodial and sympodial types. The genera Bambusa and Dendrocalamus show sympodial habit and are native to tropical and subtropical and grow well in warm dry season. On the other hand, Phyllostachys genus is monopodial and grows naturally in temperate regions. The shoots of these species are popularly consumed in the North Eastern regions of India.

Determination of amino acids is generally conducted by ionexchange chromatography, followed by post-column derivatization 
and precolumn derivatization with ninhydrin which has several disadvantages. In recent years, the analysis of amino acids using precolumn derivatization with Ortho-Phthalaldehyde (OPA) and reversedphase high-performance liquid chromatography (HPLC) separation is widely accepted as it is rapid, reliable, and stable method. The scanty data about the nutrition content including free amino acid profile on the edible shoots of different bamboo species accompanied with lack of awareness about its edibility is the reason for the nutritional potential of this plant being untapped. Free amino acid profile in the bamboo shoots has not been studied broadly, and some amino acids in limited bamboo species (Phyllostachys pubescens, Phyllostachys praecox, Sinoarundinaria nigra, Dendrocalamus latiflorus) have been investigated previously $[18,19]$. However, the amino acid profile of bamboos grown in India has not yet been determined. This study was conducted to assess the amino acid profiles of edible shoots of five species of commercially important bamboos genera growing in various geographical regions of India.

\section{MATERIAL AND METHODS}

\section{Plant collection and identification}

The fresh edible shoots of Bambusa balcooa Roxb, Dendrocalamus giganteus Munro, Dendrocalamus hamiltonii Nees and Arn. Ex Munro, Dendrocalamus membranaceus Munro, and Phyllostachys mannii Gamble were collected during the months of May to September for 4 consecutive years, i.e., 2014-2017 from upper Shillong, Meghalaya (25.5으 N, 91.89 $\mathrm{E})$; Imphal, Manipur $\left(24.66^{\circ} \mathrm{N}, 93.9^{\circ} \mathrm{E}\right)$; Forest Research Institute, Dehradun, Uttarakhand $\left(30.3^{\circ} \mathrm{N}, 78.0^{\circ} \mathrm{E}\right)$, India. The plants were identified and authenticated by the taxonomist at Department of Botany, Panjab University, Chandigarh. The selected species were also compared and authenticated from the same species of bamboos growing in P.N Mehra botanical garden, Chandigarh.

The shoots were measured for its physical characters. The average size of shoots of five species selected were $22.58-41.74 \mathrm{~cm}$ in length and $11.66-48.10 \mathrm{~cm}$ in diameter and $0.20-1.85 \mathrm{~kg}$ in weight. In laboratory, the upper hard outer culm sheaths and inedible portion of harvested shoots were peeled off and discarded and the edible part was washed with distilled water. The samples were stored in deep freezer at $-20^{\circ} \mathrm{C}$ till further analysis. The samples were lyophilized using lyophilizer (LYOQUEST 55, Skadi, Europe) with $0.10 \mathrm{~m}$ bar vacuum pressure and $-55^{\circ} \mathrm{C}$ condenser temperature for $24 \mathrm{~h}$. Lyophilized samples were then ground to fine powder using grinder and used for amino acids analysis.

\section{Chemicals and reagents}

The chemical and reagents used for analysis were acetonitrile, boric acid, disodium phosphate $(10 \mathrm{mM})$, high performance liquid chromatography (HPLC) grade methanol and water, hydrochloric acid (0.1 M), OPA, sodium hydroxide $(1 \mathrm{M})$, sodium tetraborate $(10 \mathrm{mM})$ and standard amino acids (asparagine, glutamine, ornithine, taurine, tryptophan). All the mentioned chemicals and standards were HPLC grade and obtained from Sigma Aldrich (U.S.). Pierce amino acid standard H (quantitative mixture of 17 amino acids, i.e. L-alanine, L-arginine, L-aspartic Acid, L-cysteine, L-glutamic acid, glycine, L-histidine, L-isoleucine, L-leucine, L-lysine, L-methionine, L-phenylalanine, L-proline, L-serine, L-threonine, L-tyrosine, L-valine) were purchased from Thermo Fisher Scientific (U.S.).

\section{Qualitative and quantitative estimation of free amino acids}

Qualitative and quantitative estimation of free amino acids was done by RP-UHPLC. Agilent technologies (USA) HPLC system with quaternary gradient pump (Series 1290), static volume injector together with an autosampler, and Diode Array Detector with emission at $339 \mathrm{~nm}$ was used. Data assortment, processing, and analyses were accomplished by using Open Lab Chromatography Data System EZchrome edition, version A.04.06 (Agilent technologies, USA).

\section{Sample preparation}

Sample preparation was done by using method of [20] with some modifications. $25 \mathrm{mg}$ of finely grounded lyophilized dried sample was dissolved in $25 \mathrm{ml}$ of borate buffer (pH-8.5). The samples were then kept in sonicator bath for 2 min for complete dissolution. The solution was transferred to microcentrifuge tubes and centrifuged in at 5000 r.p.m. for $5 \mathrm{~min}$ at $4^{\circ} \mathrm{C}$. The residue was then filtered by using $0.45 \mu \mathrm{m}$ membrane filters, and a clear supernatant of concentration of $1 \mathrm{mg} / \mathrm{ml}$ was obtained. This was then transferred to vials containing inserts which was then ready to be derivatized.

\section{Sample derivatization}

Amino acid derivatization and chromatographic analysis was carried out by Sharma et al. [21]. Derivatization steps were obtained using auto-sampler Agilent's 1290 infinity. For derivatization, $0.3 \mu \mathrm{l}$ standard solution or sample was used. The reaction mixture is buffered at $\mathrm{pH}$ of 10.2 using borate buffer and further derivatization was done using OPA.

\section{Chromatographic analysis}

Separation of amino acids was carried out using Zorbax eclipse plus C18 Reverse Phase $(1.8 \mu \mathrm{m})$ and $50 \mathrm{~mm} \times 2.1 \mathrm{~mm}$ column quaternary UHPLC system with modified gradient elution. Chromatographic condition was achieved under $5 \mathrm{~min}$ using $10 \mathrm{mM}$ disodium phosphate $+10 \mathrm{mM}$ sodium tetraborate $(\mathrm{pH} 8.35)$ and mixture of methanol/acetonitrile/water $(40: 40: 20, \mathrm{v} / \mathrm{v})$ at a flow rate of $0.5 \mathrm{ml} / \mathrm{min}$.

\section{Standard preparation}

Aqueous $2.5 \mathrm{mM}$ stock standards of asparagine, glutamine, ornithine, taurine, and tryptophan were prepared in $0.1 \mathrm{M}$ hydrochloric acid. $40 \mu \mathrm{l}$ of each stock standard and pierce $\mathrm{H}$ standard mix comprising 17 amino acids were mixed with $0.1 \mathrm{M}$ hydrochloric acid and obtained a last concentration of $0.1 \mathrm{mM}$ per amino acid. The working standards solution $(5,10,25,50,75,100,150 \mathrm{pmole} / \mu \mathrm{l})$ were derivatized and analyzed. Linearity of the peak areas for different concentration ranging from 5 to $150 \mathrm{pmole} / \mu \mathrm{l}$ of individual amino acid was determined. Amino acids were detected based on the retention time established for the individual amino acid under defined experimental conditions. Calculation was based on the area under peak established for a given amino acid of known concentration.

\section{Statistical analysis}

Experimental analysis was conducted in replicates of three so that variability associated with the experiment can be noted and the result is presented in the form of mean of the replicates \pm standard deviation. Data were subjected to one-way analysis of variance using PASW statistics software version 18.0. Statistically significant difference was determined by using Duncan's multiple range tests at significance level of $\mathrm{p}<0.05$.

\section{RESULTS AND DISCUSSION}

Physical characteristics of bamboo shoots

Physical dimensions in terms of weight, length, and circumference of shoots of five bamboo species are presented in Table 1. Shoot weight is directly correlated with better yield. The weight of the shoots of five examined species was found in descending order as follows: D. giganteus

Table 1: Physical characteristics of edible shoots of five bamboo species

\begin{tabular}{lllll}
\hline $\begin{array}{l}\text { S. } \\
\text { No. }\end{array}$ & Species & $\begin{array}{l}\text { Weight } \\
\text { (kg) }\end{array}$ & $\begin{array}{l}\text { Length } \\
\text { (cm) }\end{array}$ & $\begin{array}{l}\text { Basal } \\
\text { circumference } \mathbf{( c m )}\end{array}$ \\
\hline 1. & $\begin{array}{l}\text { Bambusa } \\
\text { balcooa }\end{array}$ & $1.61 \pm 0.18$ & $33.10 \pm 2.53$ & $29.30 \pm 1.44$ \\
2. & $\begin{array}{l}\text { Dendrocalamus } \\
\text { giganteus }\end{array}$ & $1.85 \pm 0.10$ & $28.75 \pm 1.24$ & $48.10 \pm 1.48$ \\
3. & $\begin{array}{l}\text { Dendrocalamus } \\
\text { hamiltonii }\end{array}$ & $0.59 \pm 0.0$ & $22.58 \pm 1.90$ & $21.35 \pm 3.73$ \\
4. & $\begin{array}{l}\text { Dendrocalamus } \\
\text { membranaceus }\end{array}$ & $1.28 \pm 0.10$ & $36.66 \pm 2.08$ & $30.33 \pm 2.30$ \\
5. & $\begin{array}{l}\text { Phyllostachys } \\
\text { mannii }\end{array}$ & $0.20 \pm 0.05$ & $41.74 \pm 11.39$ & $11.66 \pm 2.88$ \\
\hline
\end{tabular}

Data presented in mean values \pm standard deviation $(\mathrm{n}=3)$ 
$(1.85 \mathrm{~kg})>$ B. balcooa $(1.61 \mathrm{~kg})>$ D. membranaceus $(1.28 \mathrm{~kg})>$ D. hamiltonii $(0.60 \mathrm{~kg})>$ P. mannii $(0.20 \mathrm{~kg})$. The length of shoots of five species was ranged from 22.58 to $41.74 \mathrm{~cm}$ with maximum in $P$. mannii and minimum in $D$. hamiltonii. The average circumference was ranged from 11.66 to $48.10 \mathrm{~cm}$. The maximum circumference was recorded in D. giganteus and minimum in P. mannii.

Qualitative and quantitative estimation of free amino acids

The lyophilized samples of the shoots of five bamboo species, namely B. balcooa, D. giganteus, D. hamiltonii, D. membranaceus, and P. mannii were analyzed for qualitative and quantitative estimation of free amino acids using RP-UHPLC. HPLC chromatogram of fresh shoots of the five species showing peaks of different amino acids with retention time in minutes is shown in Figs. 1-5. The current analysis displayed a qualitatively homogenous profile with identification of nineteen amino acids in all the investigated species except $D$. membranaceus.

From a nutritional point of view, the amino acids can be characterized as essential, conditionally essential and non-EAAs [22]. Of 19 amino acids detected in the present study, eight were EAAs (Histidine, Isoleucine, Leucine, Lysine, Methionine, Phenylalanine, Threonine, and Valine), five were conditionally EAAs (CEAA) (Arginine, Glutamine, Glycine, Taurine, and Tyrosine), and six were non-
EAAs (Alanine, Asparagine, Aspartic acid, Glutamic acid, Serine, and Ornithine). Twelve free amino acids (six essential and six nonessential) in the shoots of $P$. praecox have been reported in the previous studies [23]. Sun et al. [24] detected two amino acids, i.e., L-phenylalanine $(269.98 \mathrm{mg} / \mathrm{kg})$ and L-tyrosine $(122.06 \mathrm{mg} / \mathrm{kg})$ in P. pubescens. Xu et al. [25] isolated two amino acids (tryptophan and phenylalanine) in other species of Phyllostachys (P. pubescens, P. iridescens, P. prominens, P. praecox). In the current study, the quantitative determination of amino acid was performed by calculating amino acids peak area of standards and analyzed samples. The results revealed the quantifiable variation in the concentration of identified free amino acids among the analyzed species.

\section{EAAs}

It is well known that humans and animals cannot synthesize all required amino acids de novo. As a result, these amino acids must be obtained through dietary intake and are classified as essential [12]. The EAA content in the shoots of five bamboo species (B. balcooa, D. giganteus, D. hamiltonii, D. membranaceus, and P. mannii) is presented in Table 2. The concentration of EAA ranged from 0.46 to $21.11 \mu \mathrm{g} / \mathrm{mg}$ d.w. in our study. Earlier studies of EAA conducted in P. pubescens revealed a range from 1.31 to $3.35 \%$ d.w. $[18,23]$. The heterogeneity in the current and previous studies might be due to the variability in geographical climatic

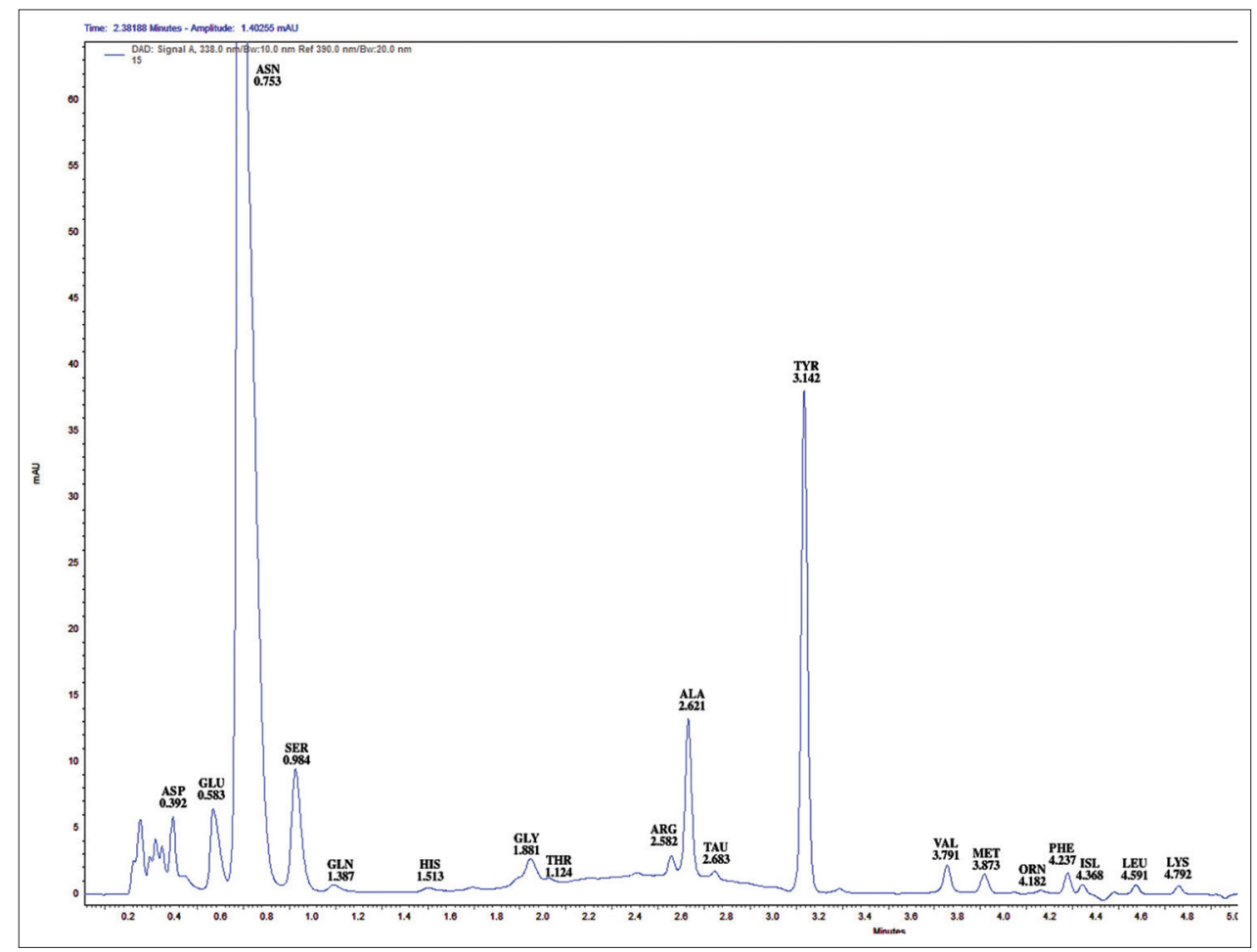

Fig. 1: High-performance liquid chromatography chromatogram of shoots of Bambusa balcooa showing peaks of different amino acids with retention time

Table 2: Essential amino acids content $(\mu \mathrm{g} / \mathrm{mg}$ dry weight) in the edible shoots of five bamboo species

\begin{tabular}{llllll}
\hline Amino acids & Bambusa balcooa & Dendrocalamus giganteus & D. hamiltonii & D. membranaceus & Phyllostachys mannii \\
\hline Histidine (His) & $1.63 \pm 0.08^{\mathrm{d}}$ & $3.66 \pm 0.27^{\mathrm{b}}$ & $2.41 \pm 0.26^{\mathrm{c}}$ & $1.77 \pm 0.10^{\mathrm{d}}$ & $4.21 \pm 0.26^{\mathrm{a}}$ \\
Isoleucine (Ile) & $1.65 \pm 0.08^{\mathrm{d}}$ & $2.45 \pm 0.11^{\mathrm{bc}}$ & $2.64 \pm 0.09^{\mathrm{b}}$ & $2.26 \pm 0.13^{\mathrm{c}}$ & $7.80 \pm 0.30^{\mathrm{a}}$ \\
Leucine (Leu) & $2.77 \pm 0.07^{\mathrm{c}}$ & $4.36 \pm 0.11^{\mathrm{b}}$ & $1.59 \pm 0.05^{\mathrm{d}}$ & $2.97 \pm 0.20^{\mathrm{c}}$ & $12.84 \pm 0.13^{\mathrm{a}}$ \\
Lysine (Lys) & $1.71 \pm 0.10^{\mathrm{c}}$ & $2.11 \pm 0.23^{\mathrm{b}}$ & $1.05 \pm 0.03^{\mathrm{d}}$ & $1.50 \pm 0.10^{\mathrm{c}}$ & $3.96 \pm 0.14^{\mathrm{a}}$ \\
Methionine (Met) & $5.48 \pm 0.88^{\mathrm{bc}}$ & $9.02 \pm 0.31^{\mathrm{a}}$ & $5.01 \pm 0.62^{\mathrm{c}}$ & $4.58 \pm 0.40^{\mathrm{c}}$ & $6.39 \pm 0.66^{\mathrm{b}}$ \\
Phenylalanine (Phe) & $1.98 \pm 0.04^{\mathrm{c}}$ & $3.63 \pm 0.15^{\mathrm{b}}$ & $2.74 \pm 0.08^{\mathrm{c}}$ & $4.03 \pm 0.13^{\mathrm{b}}$ & $7.54 \pm 1.04^{\mathrm{a}}$ \\
Threonine (Thr) & $0.46 \pm 0.03^{\mathrm{d}}$ & $2.74 \pm 0.13^{\mathrm{b}}$ & $1.28 \pm 0.05^{\mathrm{c}}$ & $\mathrm{ND}$ & $8.91 \pm 1.09^{\mathrm{a}}$ \\
Valine (Val) & $2.51 \pm 0.05^{\mathrm{c}}$ & $9.60 \pm 0.31^{\mathrm{b}}$ & $2.89 \pm 0.11^{\mathrm{c}}$ & $3.78 \pm 1.10^{\mathrm{c}}$ & $21.11 \pm 2.40^{\mathrm{a}}$ \\
\hline
\end{tabular}

Data presented in mean values \pm standard deviation $(\mathrm{n}=3)$. Values with different letters superscript in each row indicate significant differences in amino acid content among five bamboo species ( $\mathrm{p}<0.05)$, ND (Not detected) 


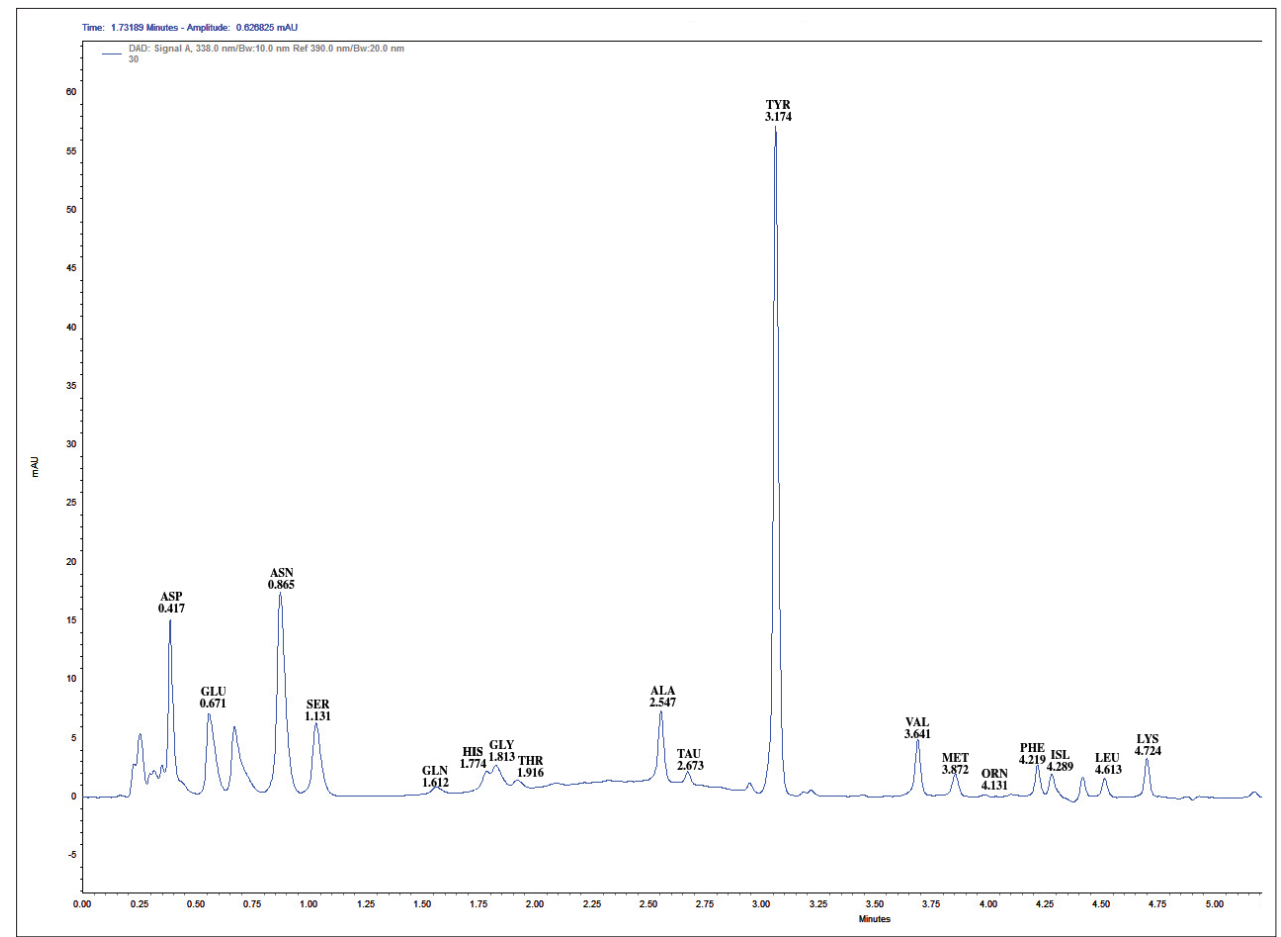

Fig. 2: High-performance liquid chromatography chromatogram of fresh shoots of Dendrocalamus giganteus showing peaks of different amino acids with retention time

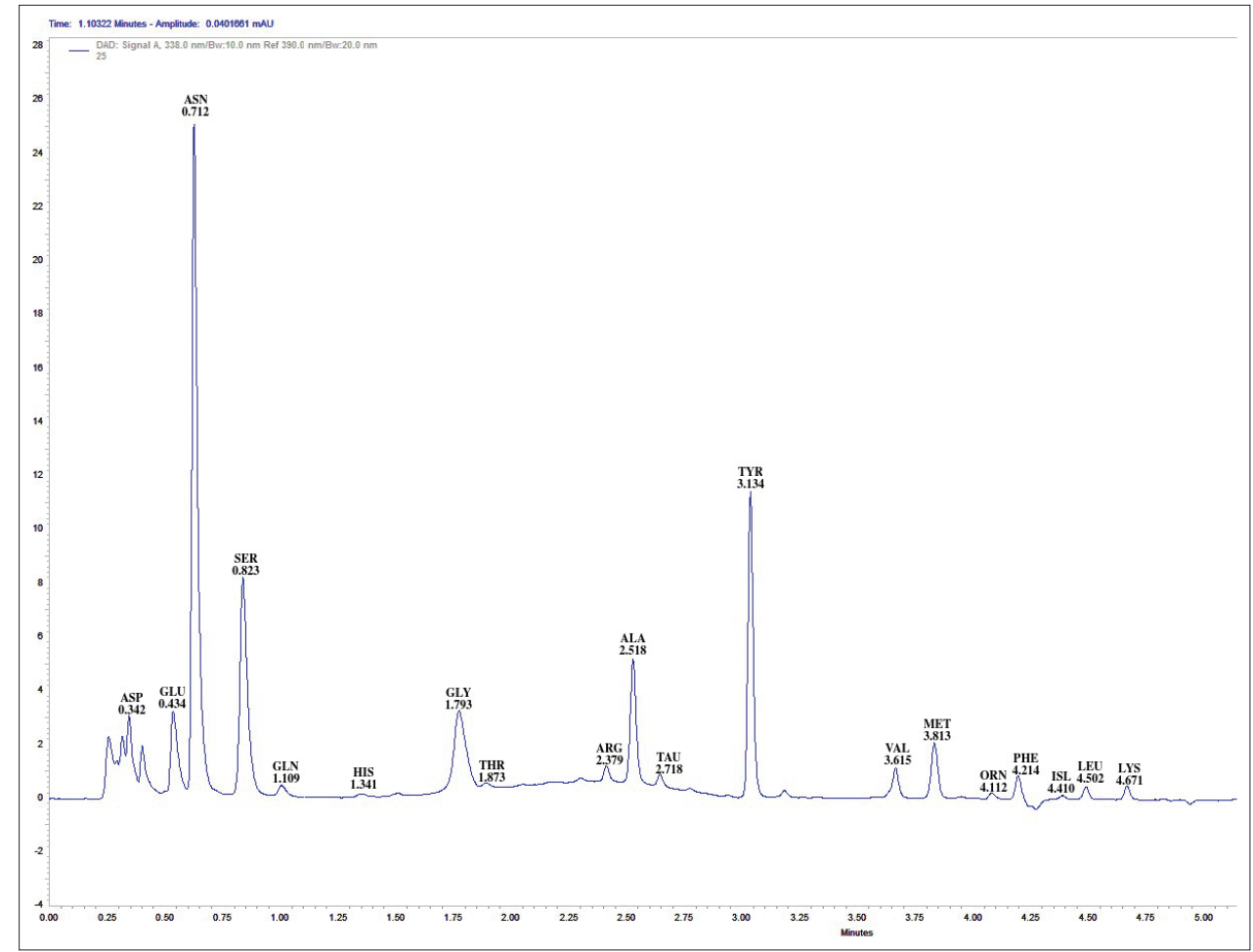

Fig. 3: High-performance liquid chromatography chromatogram of fresh shoots of Dendrocalamus hamiltonii showing peaks of different amino acids with retention time

conditions, methodologies, and the bamboo species used for evaluating amino acids.

As seen in Table 2, the results exhibited variation in the concentration of EAA among the five bamboo species with significant variances among them. Histidine ranged from 1.63 to $4.21 \mu \mathrm{g} / \mathrm{mg}$ d.w. and showed significantly $(\mathrm{p}<0.05)$ high content in $P$. mannii compared to other species. No significant difference in histidine was observed between D. membranaceus and B. balcooa. Histidine bestows antiinflammatory properties and is an efficient scavenger of free radicals and plays an antioxidative role in muscle, brain, and other tissues [26]. The content of phenylalanine varied from 1.98 to $7.54 \mu \mathrm{g} / \mathrm{mg} \mathrm{d} . \mathrm{w}$. and 


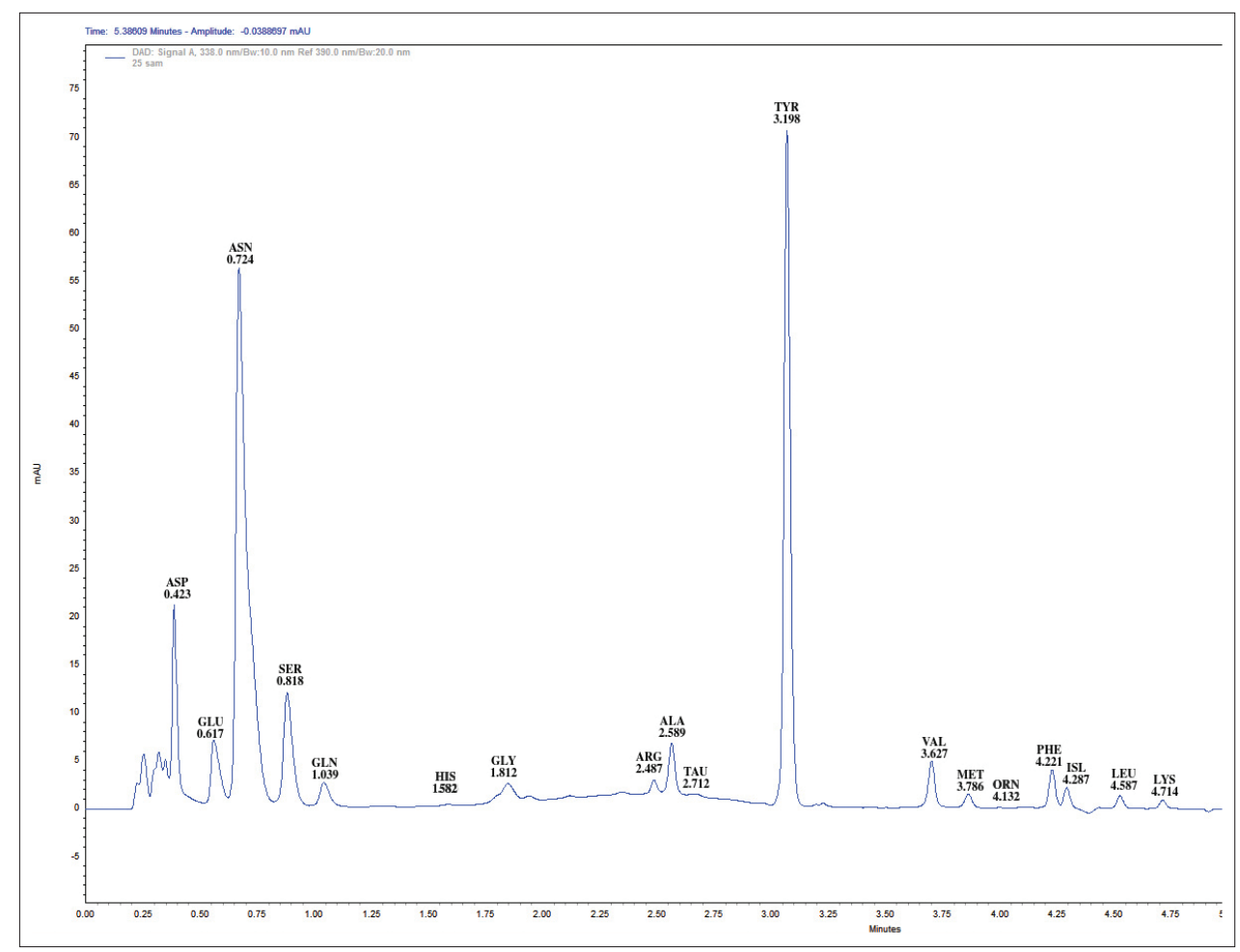

Fig. 4: High-performance liquid chromatography chromatogram of fresh shoots of Dendrocalamus membranaceus showing peaks of different amino acids with retention time

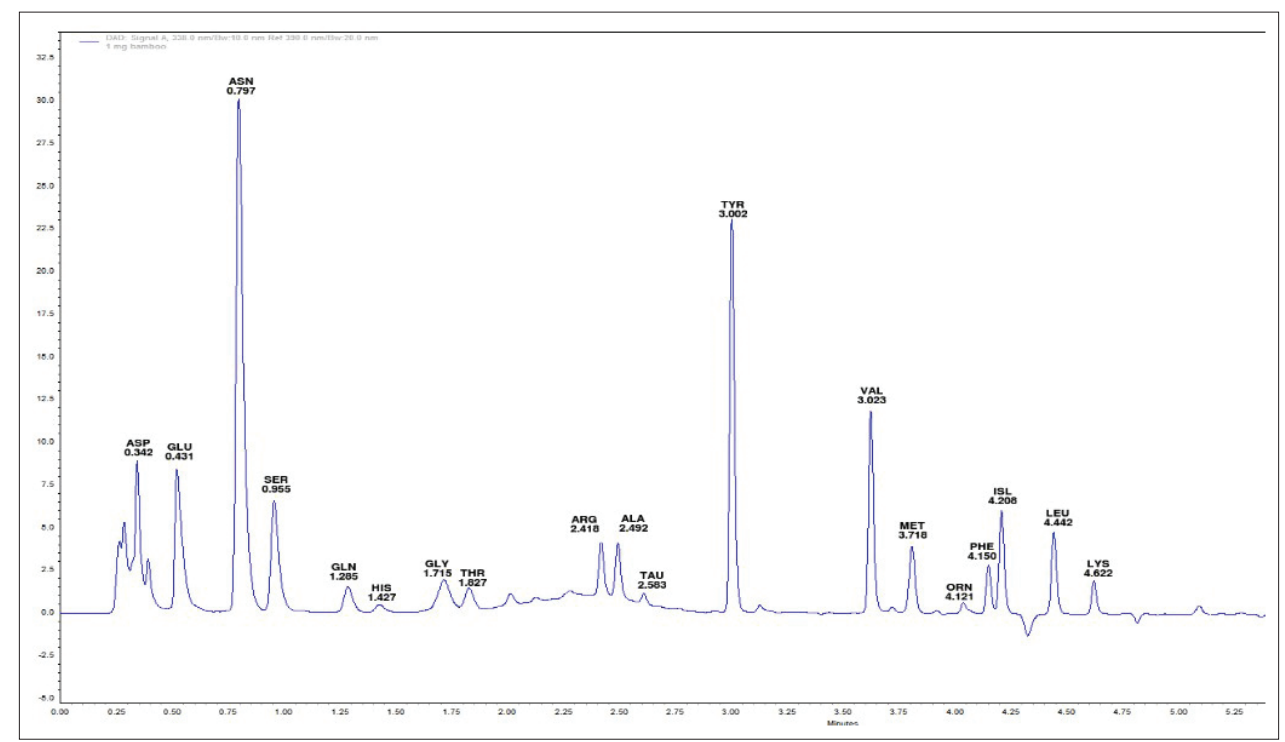

Fig. 5: High-performance liquid chromatography chromatogram of fresh shoots of Phyllostachys mannii showing peaks of different amino acids with retention time

was recorded significantly $(\mathrm{p}<0.05)$ highest in P. mannii. However, no major significant difference was observed between D. membranaceus and D. giganteus as well as between D. hamiltonii and B. balcooa. Phenylalanine was reported previously in some Phyllostachys species (P. pubescens, P. iridescens, P. prominens, P. praecox) with concentration ranged from 269.98 to $1460.93 \mathrm{mg} / \mathrm{kg}$ f.w $[24,25]$. Phenylalanine is precursor for synthesis of epinephrine, norepinephrine, dopamine, and thyroid hormones. This amino acid is also involved in modulating the suppression of T-cell immune responses [27].

Some EAAs such as lysine and threonine are potentially limited in all the major cereals and methionine is limited in legumes [28]. However, all three limiting amino acids were present in all five investigated bamboo species except threonine in $D$. membranaceus. Lysine content ranged from 1.05 to $3.96 \mu \mathrm{g} / \mathrm{mg}$ d.w. with significantly $(\mathrm{p}<0.05)$ maximum in $P$. mannii followed by D. giganteus with no statistical difference which was observed between B. balcooa and D. membranaceus. Threonine ranged from 0.46 to $8.91 \mu \mathrm{g} / \mathrm{mg}$ d.w. in the four examined species and not detected in D. membranceus. Threonine content was statistically $(\mathrm{p}<0.05)$ different among the four species with significantly high in $P$. mannii. Lysine and threonine are known to crucial for supporting intestinal integrity and immunity [29]. Methionine ranged from 4.58 to $9.02 \mu \mathrm{g} / \mathrm{mg}$ d.w. with significantly high content in D. giganteus followed by P. mannii and B. balcooa. However, no significant difference $(\mathrm{p}<0.05)$ 
was observed in the remaining two species. Methionine is imperative in mammalian nutrition as its supplementation, or restriction can mediate the natural antioxidant capacity of an organism by the formation of endogenous enzymes that reduce oxidative stress, DNA damage, cancer, cardiovascular, and neurodegenerative diseases [30]. Methionine can be a potential component of artificial feeding formulas and for the prevention of breast and colorectal cancer [31].

Isoleucine, leucine, and valine, the branched chain amino acids are nutritionally essential and have proved to be beneficial for several disorders [32]. According to a study conducted by WaskiwFord et al. [5], leucine-enriched EAAs acutely enhance post-exercise myofibrillar protein synthesis which has been suggested to be important for muscle repair and recovery. In the present study, isoleucine ranged from 1.65 to $7.80 \mu \mathrm{g} / \mathrm{mg}$ d.w. and was found significantly high in P. mannii with no significant difference $(\mathrm{p}<0.05)$ among three Dendrocalamus species. Leucine content was ranged from lowest $(1.59 \mu \mathrm{g} / \mathrm{mg}$ d.w.) in D. hamiltonii to significantly highest $(12.84 \mu \mathrm{g} / \mathrm{mg}$ d.w.) in P. mannii with no significant $(\mathrm{p}<0.05)$ difference between $D$. membranaceus and $B$. balcooa. Valine showed a wide range $(2.51$ to $21.11 \mu \mathrm{g} / \mathrm{mg}$ d.w.) with significantly highest value $(21.11 \mu \mathrm{g} / \mathrm{mg}$ d.w. $)$ in $P$. mannii followed by D. giganteus ( $9.60 \mu \mathrm{g} / \mathrm{mg}$ d.w.) with no significant $(\mathrm{p}<0.05)$ differences in remaining species. Out of all essential amino acids; valine and leucine were found in higher concentration which is in accordance to the previous reports in other species $[18,21]$. Valine and leucine exhibit anti-inflammatory activities and together stimulate the muscle growth [8] and moreover, their supplementation is common in liver cirrhosis patients [33]. Leucine enhances insulin release from pancreatic $\beta$-cells and signifies an effective pharmaconutrient for treatment and prevention of type 2 diabetes and sarcopenia [34]. Recent studies indicate that branched chain amino acids are vital for their usage as nutritional supplements and have therapeutic potential due their approved protein anabolic effects [32].

\section{CEAAs}

CEAAs generally can be synthesized in suitable amounts by the organism but must be provided from the diet to meet optimum requirements at some phases of growth. In the present study, five CEAAs were detected in the shoots, i.e., arginine, glutamine, glycine, taurine, and tyrosine (Table 3). The predominant CEAA detected in all the studied species was tyrosine. Few earlier studies in bamboos (P. pubescens, P. praecox, and $S$. nigra) also displayed abundance of tyrosine $[18,23]$.

Table 3 reveals the notable variation in the concentration for the CEAA in the edible shoots of five bamboo species. The amount of glutamine ranged from 3.40 to $9.72 \mu \mathrm{g} / \mathrm{mg}$ d.w. Significantly $(\mathrm{p}<0.05)$ highest amount was observed in $D$. hamiltonii $(9.72 \mu \mathrm{g} / \mathrm{mg}$ d.w.) while no significant $(\mathrm{p}<0.05)$ variation was seen between $P$. mannii and D. giganteus and in B. balcooa and D. membranaceus. Glycine content ranged from 3.62 to $4.84 \mu \mathrm{g} / \mathrm{mg}$ d.w. with statistically high in $B$. balcooa but did not vary significantly $(\mathrm{p}<0.05)$ in the rest of investigated species. Earlier studies in other bamboo species showed lower glycine content ranged from $0.66 \%$ to $1.02 \%$ [18]. Glutamine is a precursor for the synthesis of nucleotides and participates in acid-base homeostasis and gluconeogenesis [35]. Glycine aids in muscle recovery, prevent cartilage loss, and glycine together with glutamate are vital for maintaining intestinal integrity and immunity [29].

Taurine depicted a range from 1.33 to $9.77 \mu \mathrm{g} / \mathrm{mg}$ d.w. Significantly high taurine $(9.77 \mu \mathrm{g} / \mathrm{mg}$ d.w.) was detected in the shoots of $P$. mannii followed by $D$. giganteus $(7.77 \mu \mathrm{g} / \mathrm{mg}$ d.w.). In the rest of three species, taurine showed no major significant $(\mathrm{p}<0.05)$ variation. Taurine was not identified in previous studies in bamboos and is being reported for the $1^{\text {st }}$ time. Unlike other amino acids, taurine has amino and sulfonic group instead of carboxylic group. Taurine is linked with growth and functions of retina, skeletal, cardiovascular muscle, and central nervous system with plentiful protective bioactive functions [36] and has antioxidant, antimicrobial, and anti-inflammatory properties $[9,10]$.

Arginine ranged from 1.64 to $14.70 \mu \mathrm{g} / \mathrm{mg}$ d.w. and was significantly high in P. mannii (14.70 $\mu \mathrm{g} / \mathrm{mg}$ d.w.) followed by B. balcooa $(7.39 \mu \mathrm{g} / \mathrm{mg} \mathrm{d.w.})$ with no significant $(\mathrm{p}<0.05)$ variation among three Dendrocalamus species. Previous findings in P. pubescens and S. nigra species reported lower values (2.37 to $4.22 \%$ ) of arginine [18]. Arginine exert influence on blood pressure and its supplementation depicts glucoregulatory and insulinotropic effects in diabetic patients [37-38]. It is also known to stimulate secretion of growth hormones, improves fertility and immunity and treat metabolic syndromes [39]. Tyrosine ranged from 29.41 to $74.64 \mu \mathrm{g} / \mathrm{mg}$ d.w. The significantly $(\mathrm{p}<0.05)$ highest values $(74.64 \mu \mathrm{g} / \mathrm{mg}$ d.w.) were recorded in D. membranaceus and variation was insignificant among $P$. mannii, D. giganteus, and $D$. hamiltonii. The lowest values (29.41 $\mu \mathrm{g} / \mathrm{mg}$ d.w.) were recorded in B. balcooa. Previous studies in other species indicated the range of tyrosine from $19.86 \%$ to $26.81 \%$ [18]. Sun et al. [24] identified only L-tyrosine (122.06 mg/kg) in fresh shoots of $P$. pubescens. The concentration showed wide variation among different studies which might be due to differences in sample preparation, species, and analytical methods. Phenylketonuria patients cannot synthesize tyrosine from phenylalanine due to deficiency of the hepatic enzyme (phenylalanine 4-monooxygenase), and therefore, tyrosine is CEAAs for therapeutic intervention in foods for phenylketonuria patients [40]. Moreover, tyrosine is involved in melanin synthesis, improving brain function, treating depression, and brain disorders by the production of catecholamines such as dopamine and adrenaline [41].

\section{Non-EAAs}

Non-EAAs (NEAA) are synthesized de novo in the body and therefore not diet dependent. Some NEAA may become essential under stress conditions and catabolic states. The traditional categorization of amino acids as EAA or NEAA has key conceptual restrictions in protein

Table 3: Conditionally essential and non-essential amino acids content ( $\mu \mathrm{g} / \mathrm{mg}$ dry weight) in the edible shoots of five bamboo species

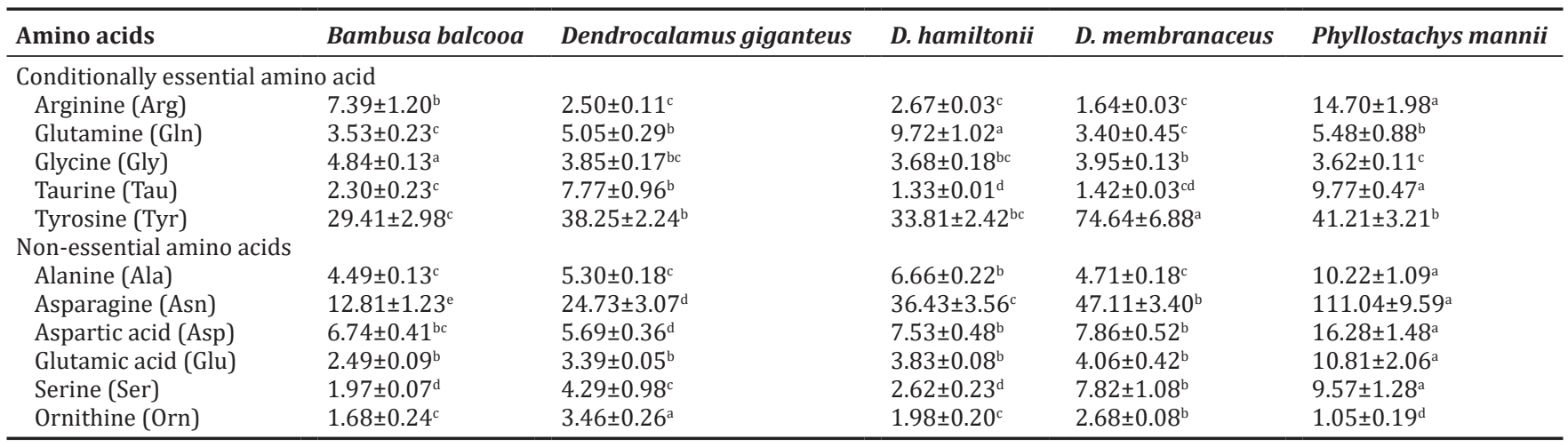

Data presented in mean values \pm standard deviation $(n=3)$. Values with different letters superscript in each row indicate significant differences in amino acid content among five bamboo species $(\mathrm{p}<0.05)$ 
nutrition. However, emerging evidence displays that conventionally classified NEAA plays vital roles in regulating gene expression, cell signaling pathways, DNA and protein synthesis, metabolism of dietary nutrients, endocrine status, women and men fertility, acid-base balance, antioxidative activities, detoxification of metabolites, neurotransmission, and immunity [42,43]. Hence, the classical concept of the perfect protein should comprise both EAA and NEAA to enhance food efficacy, growth, and health of humans and animals.

The concentration of NEAA (alanine, asparagine, aspartic acid, glutamic acid, serine, and ornithine) analyzed is presented in Table 3. The concentration of alanine ranged from 4.49 to $10.22 \mu \mathrm{g} / \mathrm{mg}$ d.w. The amount was significantly highest in P. mannii followed by D. hamiltonii and the difference was insignificant among rest of the species. In previous studies, the amount of alanine reported was between 3.8\% and $5.76 \%$ [18]. Alanine is a chief precursor for gluconeogenesis in the liver, maintains glucose and nitrogen levels, and protects cells from being damaged during intense aerobic activity [35]. Among all amino acids, asparagine was the predominant amino acid in the shoots and depicted a wide range, i.e. 12.81 to $111.04 \mu \mathrm{g} / \mathrm{mg}$ d.w. The content varied statistically $(\mathrm{p}<0.05)$ among the five species with significantly high content in P. mannii and least in B. balcooa. The dominance of asparagine in our study is comparable to the previous reports in other species of bamboos [18]. Asparagine plays a vital role in ammonia detoxification, fatigue relieving, maintaining immunity, nervous system, and brain functioning [44]

In the five analyzed species, the concentration of aspartic acid and glutamic acid ranged from 5.69 to $16.28 \mu \mathrm{g} / \mathrm{mg}$ d.w. and 2.49$10.81 \mu \mathrm{g} / \mathrm{mg}$ d.w., respectively. The amount of both amino acids was significantly high $(\mathrm{p}<0.05)$ in $P$. mannii compared to other species. However, no significant $(\mathrm{p}<0.05)$ difference in aspartic acid content among three species (B. balcooa, D. hamiltonii, and D. membranaceus) and glutamic acid content among the remaining four species was observed. Previous studies in other species had reported the range of aspartic and glutamic acid from $0.86 \%$ to $2.21 \%$ and $3.40 \%$ to $4.61 \%$, respectively [18]. Glutamic and aspartic acid is implicated in the development of nervous system, neurotransmission signaling, increasing testosterone levels, promoting hormone synthesis, reducing fat stores, and preventing cardiovascular disorders [45].

A wide variation (1.97-9.57 $\mu \mathrm{g} / \mathrm{mg}$ d.w.) in serine content was observed with significantly maximum in $P$. mannii followed by D. membranaceus, $D$. giganteus with insignificant $(\mathrm{p}<0.05)$ variation in $D$. hamiltonii and B. balcooa. In earlier reports of Park and Jhon [18], serine content ranged from $2.36 \%$ to $5.19 \%$. The amount of ornithine was ranged from 1.05 to $3.46 \mu \mathrm{g} / \mathrm{mg}$ d.w. in five species. The content was significantly $(\mathrm{p}<0.05)$ high in D. giganteus and lowest in P. mannii. The content did not vary significantly $(\mathrm{p}<0.05)$ between $D$. hamiltonii and B. balcooa. Ornithine is vital for boosting muscle growth, healing wounds, preventing sleep disorders, and combating stress and fatigue [46]. Ornithine supports the treatment of individuals recovering from severe physical trauma and beneficial for patients with hepatic encephalopathy, a life-threatening problem of liver cirrhosis [47].

Extensive research and continuously accumulating evidence have highlighted the critical role of NEAAs in the pathology of cancer. Numerous novel approaches to target NEAA metabolism are presently in clinical trials. Dietary management of NEAA metabolism is also an effective strategy for preventing tumor development either as a primary treatment choice or to develop the potentiality of other chemotherapies [48]. Considering all the analyzed species, the amount of all free amino acids except methionine, tyrosine, and ornithine was highest in P. mannii compared to the other investigated species which indicates that, to a certain extent, this species has more nutritional and medicinal values. D. giganetus had second richest content of amino acid followed by $P$. mannii, also abundant in methionine and ornithine while $D$. membranaceus was rich in tyrosine. Thus, $P$. mannii and $D$. giganteus are promising bamboo species whose shoots can be included in the diet and used for fortifying food products to improve their nutritional quality.

\section{CONCLUSION}

Bamboo shoots have great prospects to combat the deficiency of essential and CEAAs, especially in vegetarian diets. This is the first report regarding the presence of 19 free amino acids (aspartic acid, glutamic acid, asparagine, glutamine, serine, arginine, glycine, threonine, alanine, tyrosine, histidine, lysine, valine, leucine, isoleucine, methionine, phenylalanine, taurine, and ornithine) in edible shoots of five bamboos species. Of the five species, $P$. mannii was best compared to the other bamboo species in amino acid content and can be used for formulating plant-based food products. Amino acids have various aroma, flavors, health and therapeutic properties can contribute to the basis for further expansion of these bamboos and imminent potential in applications of food in various formulations and supplementation in foods which lack in one or more EAAs as well as in pharmaceuticals. Furthermore, the present exploration of amino acids enriches the knowledge about the biochemical composition of bamboos shoots, which might also be of interest for other scientists as a preliminary information for further investigations.

\section{ACKNOWLEDGMENTS}

Authors would like to acknowledge University Grant Commission, Govt of India, for providing financial assistance.

\section{AUTHOR'S CONTRIBUTIONS}

KRR, AP, SVA designed the experimental study, validated methodology and software, and carried out the analysis. KRR, NC, MSB contributed to the writing, reviewing, editing of the manuscript. All authors have approved the final manuscript.

\section{CONFLICTS OF INTEREST}

There are no conflicts of interest.

\section{AUTHOR'S FUNDING}

This research is funded by University Grant Commission (grant no F7- 151/2007), Govt. of India.

\section{REFERENCES}

1. Green CL, Lamming DW. Regulation of metabolic health by essential dietary amino acids. Mech Ageing Dev 2019;177:186-200.

2. Dai Z, Wu Z, Hang S, Zhu W, Wu G. Amino acid metabolism in intestinal bacteria and its potential implications for mammalian reproduction. Mol Hum Reprod 2015;21:389-409.

3. Rose AJ. Amino acid nutrition and metabolism in health and disease. Nutrients 2019;11:2623.

4. Park H, Park G, Jeon W, Ahn JO, Yang YH, Choi KY. Whole-cell biocatalysis using cytochrome $\mathrm{P} 450$ monooxygenases for biotransformation of sustainable bioresources (fatty acids, fatty alkanes, and aromatic amino acids). Biotechnol Adv 2020;40:107504.

5. Waskiw-Ford M, Hannaian S, Duncan J, Kato H, Abou S, Locke M, et al. Leucine-enriched essential amino acids improve recovery from post-exercise muscle damage independent of increases in integrated myofibrillar protein synthesis in young men. Nutrients 2020;12:1061.

6. Alagawany M, Elnesr SS, Farag MR, Tiwari R, Yatoo MI, Karthik K, et al. Nutritional significance of amino acids, vitamins and minerals as nutraceuticals in poultry production and health-a comprehensive review. Vet Q 2021;41:1-29.

7. Koopman R, Elango R. Distinct roles for dietary protein and amino acids in health and disease. Curr Opin Clin Nutr Metab Care 2021;24:53-4.

8. Wu G. Amino acids: Metabolism, functions, and nutrition. Amino Acids 2009:37:1-17.

9. Marcinkiewicz J, Kontny E. Taurine and inflammatory diseases. Amino Acids 2014:46:7-20.

10. Seol SI, Kim HJ, Choi EB, Kang IS, Lee HK, Lee JK, Kim C, et al. Taurine protects against postischemic brain injury via the antioxidant activity of taurine chloramine. Antioxidants (Basel) 2021;10:372 . 
11. Elango R, Laviano A. Protein and amino acids: Key players in modulating health and disease. Curr Opin Clin Nutr Metab Care 2017;20:69-70.

12. Galili G, Amir R, Fernie AR. The regulation of essential amino acid synthesis and accumulation in plants. Annu Rev Plant Biol 2016;67: 153-78.

13. de Filippis LF. Underutilized and neglected crops: Next generation sequencing approaches for crop improvement and better food security. In: Ozturk M, Hakeem K, Ashraf M, Ahmad M, editors. Global Perspectives on Underutilized Crops. Switzerland: Springer; 2018. p. 287-380.

14. Ghosh GK. Bamboo: The wonderful grass. New Delhi: APH Publishing; 2014.

15. Nirmala C, Bisht MS. 10 WBC reports: Bamboo: A prospective ingredient for functional food and nutraceuticals. Bamboo J 2017;30:82-9

16. Behera P, Balaji S. Health benefits of fermented bamboo shoots: The twenty-first century green gold of Northeast India. Appl Biochem Biotechnol 2021;26:1-3.

17. Collins RJ, Keilar S. The Australian bamboo shoots industry: A supply chain approach. A report for rural industries research and development corporation, Australia. J Community Med 2005;33:9-10.

18. Park EJ, Jhon DY. The nutritional composition of bamboo shoots and the effects of its fiber on intestinal microorganisms. Korean J Food Cult 2013;28:502-11.

19. Zheng J, Zhang F, Zhou C, Chen G, Lin M, Kan J. Changes in amino acid contents, texture and microstructure of bamboo shoots during pickling process. Int J Food Sci Technol 2013;48:1847-53.

20. Lopez-Cervantes J, Sánchez-MachadoDI, Rosas-RodríguezJA.Analysis of free amino acids in fermented shrimp waste by high-performance liquid chromatography. J Chromatogr A 2006;1105:106-10.

21. Sharma G, Attri SV, Behra B, Bhisikar S, Kumar P, Tageja M, et al. Analysis of 26 amino acids in human plasma by HPLC using AQC as derivatizing agent and its application in metabolic laboratory. Amino Acids 2014;46:1253-63.

22. Otten JJ, Hellwig JP, Meyers LD. Dietary Reference Intakes: The Essential Guide to Nutrient Requirements. United States: National Academies Press; 2006.

23. Zhang JJ, Ji R, Hu YQ, Chen JC, Ye XQ. Effect of three cooking methods on nutrient components and antioxidant capacities of bamboo shoot (Phyllostachys praecox C.D. Chu et C.S. Chao). J Zhejiang Univ Sci B 2011;12:752-9.

24. Sun J, Ding ZQ, Gao Q, Xun H, Tang F, Xia ED. Major chemical constituents of bamboo shoots (Phyllostachys pubescens): Qualitative and quantitative research. J Agric Food Chem 2015;64:2498-505.

25. Xu XB, Tang F, Guo XF, Wang J, Yao X, Sun J, et al. Isolation, identification and determination of six nucleosides and two amino acids from bamboo shoots of Gramineae Phyllostachys prominens (WY Xiong). Trop J Pharm Res 2015;14:2239-46.

26. Hasegawa S, Ichiyama T, Sonaka I, Ohsaki A, Okada S, Wakiguchi H, et al. Cysteine, histidine and glycine exhibit anti-inflammatory effects in human coronary arterial endothelial cells. Clin Exp Immunol 2012;167:269-74.

27. Yang BH, Wang X, Ren X. Amino acid metabolism related to immune tolerance by MDSCs. Int Rev Immunol 2012;31:177-83.

28. Leinonen I, Iannetta PP, Rees RM, Russell W, Watson C, Barnes AP. Lysine supply is a critical factor in achieving sustainable global protein economy. Front Sustain Food Syst 2019;3:27.
29. Rhoads JM, Wu, G. Glutamine, arginine, and leucine signaling in the intestine. Amino Acids 2009;37:111-22.

30. Martínez Y, Li X, Liu G, Bin P, Yan W, Más D, et al. The role of methionine on metabolism, oxidative stress, and diseases. Amino Acids 2017:49:2091-8.

31. van de Poll MC, Dejong CH, Soeters PB. Adequate range for sulfurcontaining amino acids and biomarkers for their excess: Lessons from enteral and parenteral nutrition. J Nutr 2006;136:1694S-700S.

32. Holecek M. Branched-chain amino acids in health and disease: Metabolism, alterations in blood plasma, and as supplements. Nutr Metab (Lond) 2018;15:33.

33. Holecek M. Branched-chain amino acid supplementation in treatment of liver cirrhosis: Updated views on tips how attenuate their harmful effects on cataplerosis and ammonia formation. Nutrition 2017;41:80-5.

34. Leenders M, Loon LJ. Leucine as a pharmaconutrient to prevent and treat sarcopenia and Type 2 diabetes. Nutr Rev 2011;69:675-89.

35. Holecek M. Relation between glutamine, branched-chain amino acids, and protein metabolism. Nutrition 2002;18:130-3.

36. Ripps H, Shen W. Review: Taurine: A "very essential" amino acid. Mol Vis 2012;18:2673-86.

37. Krause M, Fayh AP, Reischak-Oliveira A. L-arginine usage in Type I diabetes: From the autoimmune event to human dietary supplementation. In: L-Arginine in Clinical Nutrition. Switzerland: Humana Press; 2017. p. 395-406.

38. Newsholme P, Keane KN, Elahy M, Cruzat VF. L-arginine, pancreatic beta cell function, and diabetes: Mechanisms of stimulated insulin release and pathways of metabolism. In: Patel V, Preedy V, Rajendram R, editors. In: L-Arginine in Clinical Nutrition. Switzerland: Humana Press; 2017. p. 85-4.

39. Fu WJ, Haynes TE, Kohli R. Dietary L-arginine supplementation reduces fat mass in zucker diabetic fatty rats. J Nutr 2005;135:714-21.

40. Jurecki ER, Cederbaum S, Kopesky J, Perry K, Rohr F, SanchezValle A, et al. Adherence to clinic recommendations among patients with phenylketonuria in the United States. Mol Genet Metab 2017;120:190-7.

41. Harmer CJ, McTavish SF, Clark L, Goodwin GM, Cowen PJ. Tyrosine depletion attenuates dopamine function in healthy volunteers. Psychopharmacology 2001;154:105-11.

42. Hou Y, He W, Hu S, Wu G. Composition of polyamines and amino acids in plant-source foods for human consumption. Amino Acids 2019;51:1153-65.

43. Wu G, Wu Z, Dai Z, Yang Y, Wang W, Liu C. Dietary requirements of "nutritionally non-essential amino acids" by animals and humans. Amino Acids 2013;44:1107-13

44. Wu G. Amino Acids: Biochemistry and Nutrition. Boca Raton, Florida: CRC Press; 2013.

45. Jiang XL, Tian JC, Zhi HA, Zhang WD. Protein content and amino acid composition in grains of wheat-related species. Agric Sci China 2008;7:272-9

46. Harada D, Nagamachi S, Aso K, Ikeda K, Takahashi Y, Furuse M. Oral administration of 1-ornithine increases the content of both collagens constituting amino acids and polyamines in mouse skin. Biochem Biophys Res Commun 2019;512:712-5.

47. Jalan R, Jalan KN. Compositions Comprising Ornithine and Phenylacetate or Phenylbutyrate for Treating Hepatic Encephalopathy, U.S. Patent No. 10, 610, 506. Washington, DC: U.S. Patent and Trademark Office; 2020.

48. Choi BH, Coloff JL. The diverse functions of non-essential amino acids in cancer. Cancers (Basel) 2019;11:675. 